\title{
Classification systems for causes of stillbirth and neonatal death, 2009-2014: an assessment of alignment with characteristics for an effective global system
}

Susannah Hopkins Leisher ${ }^{1,2^{*}}$, Zheyi Teoh ${ }^{1}$, Hanna Reinebrant ${ }^{1,2}$, Emma Allanson ${ }^{3,4}$, Hannah Blencowe ${ }^{5}$, Jan Jaap Erwich 2,6, J. Frederik Frøen 7,8, Jason Gardosi ${ }^{9}$, Sanne Gordijn ${ }^{2,6}$, A. Metin Gülmezoglü ${ }^{3}$,

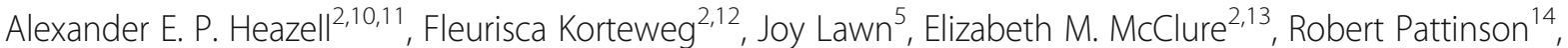
Gordon C. S. Smith ${ }^{15}$,̈̈ze Tunçalp ${ }^{3}$, Aleena M. Wojcieszek ${ }^{1,2}$ and Vicki Flenady ${ }^{1,2}$

\begin{abstract}
Background: To reduce the burden of 5.3 million stillbirths and neonatal deaths annually, an understanding of causes of deaths is critical. A systematic review identified 81 systems for classification of causes of stillbirth (SB) and neonatal death (NND) between 2009 and 2014. The large number of systems hampers efforts to understand and prevent these deaths. This study aimed to assess the alignment of current classification systems with expert-identified characteristics for a globally effective classification system.
\end{abstract}

Methods: Eighty-one classification systems were assessed for alignment with 17 characteristics previously identified through expert consensus as necessary for an effective global system. Data were extracted independently by two authors. Systems were assessed against each characteristic and weighted and unweighted scores assigned to each. Subgroup analyses were undertaken by system use, setting, type of death included and type of characteristic.

Results: None of the 81 systems were aligned with more than 9 of the 17 characteristics; most (82\%) were aligned with four or fewer. On average, systems were aligned with $19 \%$ of characteristics. The most aligned system (Frøen 2009-Codac) still had an unweighted score of only 9/17. Alignment with individual characteristics ranged from 0 to $49 \%$. Alignment was somewhat higher for widely used as compared to less used systems ( $22 \%$ v $17 \%$ ), systems used only in high income countries as compared to only in low and middle income countries (20\% vs $16 \%$ ), and systems including both SB and NND (23\%) as compared to NND-only (15\%) and SB-only systems (13\%). Alignment was higher with characteristics assessing structure (23\%) than function (15\%).

(Continued on next page)

\footnotetext{
* Correspondence: sh12164@cumc.columbia.edu

${ }^{1}$ Mater Research Institute, The University of Queensland (MRI-UQ), Brisbane, Australia

${ }^{2}$ International Stillbirth Alliance, Millburn, USA

Full list of author information is available at the end of the article
} 
(Continued from previous page)

Conclusions: There is an unmet need for a system exhibiting all the characteristics of a globally effective system as defined by experts in the use of systems, as none of the 81 contemporary classification systems assessed was highly aligned with these characteristics. A particular concern in terms of global effectiveness is the lack of alignment with "ease of use" among all systems, including even the most-aligned. A system which meets the needs of users would have the potential to become the first truly globally effective classification system.

Keywords: Stillbirth, Neonatal death, Perinatal death, Classification, Classification system, Cause

\section{Background}

Classification of the causes of the 5.3 million perinatal deaths (stillbirths and neonatal deaths) that occur each year is critical to reducing these deaths; it increases our understanding of underlying causes and enables comparison of causes within and between countries $[1,2]$. In a related manuscript, we describe a systematic review which identified 81 classification systems for causes of stillbirth and neonatal death (in addition to the World Health Organization (WHO) International Classification of Diseases 10th revision (ICD-10)) that were created, modified, and/or used between 2009 and 2014, all with widely varying characteristics. Stated reasons for system development included the need to add features and missing categories, increase accuracy, reach new user groups, enable identification of underlying causes, and reduce the number of "unexplained" deaths [3].

The review found that alignment of systems with general principles of the ICD, the global standard for cause of death assignment and reporting, was somewhat limited, with just $21 \%$ of systems using ICD codes. Systems were also found to have quite low coverage as measured by data from published reports between 2009 and 2014 showing numbers of deaths classified by each system, including in high-burden countries. The majority of systems were used only in the regions (high- or low/medium-income countries) where they had been developed.

Data produced by different systems are often incompatible, hampering efforts to increase understanding of the global burden of specific causes of perinatal deaths $[4,5]$. In 2008, the WHO began work to rationalize the global approach to classification of causes of perinatal death. This approach, the ICD for Perinatal Mortality, or ICD-PM, is now in the testing phase [6]. As part of this effort, an iterative process to identify characteristics for an effective global classification system for causes of stillbirth (SB) and neonatal death (NND) was undertaken, and a global panel of experts in perinatal death classification identified 17 such characteristics (reported in this series; see Wojcieszek et al. [7]).

This is the second part of a two-part study. Part one was a systematic review of classification systems for causes of SB and NND created or used between 2009 and 2014; results are presented in this series [3].

The aim of the present study was to assess the alignment of identified classification systems against the expert-identified characteristics in order to inform work towards a globally effective approach for classification of causes of SB and NND.

\section{Methods}

\section{Systems assessed}

Eighty-one new, modified or used systems for SB and/or NND were identified through a systematic literature review reported in this series (see [3] for the methodology and results of this systematic review, including the PRISMA flowchart, and Additional file 1 for details of included systems). Throughout this paper, systems are referred to by first author and year of publication of the source document, e.g. "De Galan-Roosen 2002", which is a standard way of labelling studies in systematic reviews, i.e. Cochrane. The many co-authors of some systems are named in the relevant citation.

\section{Outcome measures}

1. Frequency of system alignment with individual characteristics for an effective global classification system;

2. Weighted and unweighted scores measuring system alignment against the set of all 17 characteristics.

The characteristics were those developed through expert consultation as reported by Wojcieszek et al. [7]. Ten characteristics related to systems' structure, assessing comprehensiveness, relevance, validity, and 
sufficiency of detail for understanding cause of death. The remaining seven characteristics related to systems' functioning, assessing reliability, accessibility, and value to users. In this paper, we assess alignment against the penultimate list of characteristics reported by Wojcieszek et al., which comprised eight structural characteristics and nine functional characteristics, as this was the format for which weights (percent agreement by the expert panel) were available.

Following are definitions of some terms used in this article:

- System: Any approach to classifying causes of neonatal deaths and/or stillbirths that was described by authors of included papers as a "system" or "approach", and/or that included a clearly delineated list of causes separated from the data.

- Modified system: Any system that was created as a result of making changes to an existing system, where:

- the system presented was described by the authors as a modification of an existing system, or

- it was apparent that the system had been modified, despite the authors stating that the system was unchanged from its original form (e.g. different number of levels, number of categories at the top level, meaning of categories, etc.).

- New system: Any system that was created without modifying an existing system.

- Used system: A system that was used for any purpose (e.g. clinical, research) other than purely developmental (e.g. testing for reliability).

- Global system: Any system used to classify or estimate causes of stillbirths and neonatal deaths in all countries for which data is available.

- National system:

- used by a national government for annual reporting of causes for the majority ( $>50 \%$ )

of SB and/or NND nationwide, or

$\circ$ used by any research group (e.g. the United States Agency for International Development, USAID, or the United Nations Children's Fund, UNICEF) to classify causes of death

- as reported by Demographic and Health Surveys (DHS) in at least one year, where DHS data is assumed to be nationally representative, or
- of the majority (>50\%) of SB and/or NND that occur in a country in at least one year, or

- otherwise stated to be a system developed on purpose for national government use.

- Widely used system: any system used to classify $1000+$ deaths and/or in 2+ countries between 2009 and 2014.

- Level: Some systems may have a single "level" of causes and other systems may have several levels of causes, with the top level listing more general causes and each lower level listing sub-categories within a given general cause. For example, classifying the cause of a SB or NND in a system with multiple levels would mean that a set of causes, from most general (taken from the top level) to most specific (taken from the lowest level), would be selected, e.g. "congenital anomaly" from the top level and then more detail on that cause via assignation of a sub-category at the next level down, e.g. "trisomy 13 ".

\section{Data collection and analysis}

Rules were developed to extract variables to measure the 17 characteristics using information available in published reports (see Table 1 for a summary of rules, and Additional file 2 for greater detail).

Each system was assessed for alignment with individual characteristics and categorized as either "aligned" or "not aligned". Frequency of system alignment with individual characteristics was assessed. Overall system alignment with the full set of 17 characteristics was assessed using two measures: a weighted and an unweighted score. The unweighted score for a system was calculated by adding the total number of characteristics with which a system was aligned. The weighted score was equal to the total of the weights for each characteristic with which the system was aligned, where the weights represented the percentage of experts who had voted to include that characteristic, as reported by Wojcieszek et al. ([7]). Thus, if all experts agreed to include a characteristic, its weight was 1 , and if $80 \%$ agreed, its weight was 0.80 . The maximum possible unweighted and weighted scores were 17 and 15.64 , respectively.

Sensitivity to cut-offs for quantitative variables was assessed by reanalyzing system alignment at higher and lower cut-offs and comparing the resulting lists of mostaligned systems. Sensitivity analyses were also undertaken to determine the effect of excluding variables judged to measure a given characteristic less well 
Table 1 Summary of how alignment was assessed

\begin{tabular}{|c|c|c|c|c|}
\hline Characteristics & Weight & Variables used to assess alignment & Aligned if & $\begin{array}{l}\text { Judgment of variable accuracy } \\
\text { as a measure of alignment }\end{array}$ \\
\hline \multicolumn{5}{|l|}{ Structural characteristics } \\
\hline $\begin{array}{l}\text { A global system must use rules to ensure } \\
\text { valid assignment of cause of death } \\
\text { categories }\end{array}$ & .98 & Rules available? & Yes & Strong \\
\hline \multirow{4}{*}{$\begin{array}{l}\text { A global system must be able to work with } \\
\text { all levels of data (from both low-income and } \\
\text { high-income countries), including minimal } \\
\text { levels }\end{array}$} & .98 & & $\begin{array}{l}\text { Yes for all three } \\
\text { variables }\end{array}$ & \\
\hline & & Used in both HIC and LMIC? & & Strong \\
\hline & & Used with verbal autopsy? & & Strong \\
\hline & & Used in $>1$ LMIC? & & Weak \\
\hline $\begin{array}{l}\text { A global system must ensure cause of death } \\
\text { categories are relevant in all settings }\end{array}$ & .96 & Used in both HIC and LMIC? & Yes & Weak \\
\hline \multirow{3}{*}{$\begin{array}{l}\text { A global system must require associated } \\
\text { factors to be recorded and clearly } \\
\text { distinguished from causes of death }\end{array}$} & .94 & & $\begin{array}{l}\text { Yes for both } \\
\text { variables below }\end{array}$ & \\
\hline & & Associated factors included? & & Strong \\
\hline & & $\begin{array}{l}\text { Distinguishes associated factors } \\
\text { from causes? }\end{array}$ & & Strong \\
\hline $\begin{array}{l}\text { A global system must distinguish between } \\
\text { antepartum and intrapartum conditions }\end{array}$ & .90 & Distinguishes IP from AP? & Yes & Strong \\
\hline A global system should record the level of & .86 & Records type of data used? & Yes & Strong \\
\hline
\end{tabular}
data available to assign the cause of death (e.g. verbal autopsy only, placental histology, autopsy, etc.)

7 A global system must have multiple levels of causes of death, with a small number of main categories

As below

.80

8 A global system must include a sufficiently comprehensive list of categories to result in a low proportion of deaths classified as "other"

Functional characteristics

9 A global system must be easy to use, and 1 produce data that are easily understood and valued by users

10 A global system must have clear guidelines 1 for use and definitions for all terms used
Number of causes

Number of levels

$\%$ "other"

$\begin{array}{ll}\leq 10 & \text { Strong } \\ 2+ & \text { Strong }\end{array}$

As below

$\begin{array}{lll}\begin{array}{l}\text { \# deaths classified/\# countries } \\ \text { of use }\end{array} & \begin{array}{l}500+\text { cases and/ } \\ \text { or } 2+\text { countries }\end{array} & \text { Weak } \\ \text { Definitions available? } & \text { Yes } & \text { Weak } \\ \text { Rules available? } & \text { Yes } & \text { Weak } \\ \text { National? } & \text { Yes } & \text { Weak } \\ & \begin{array}{l}\text { Yes for both } \\ \text { variables below }\end{array} & \\ & & \text { Strong } \\ \text { Definitions available? } & & \text { Strong } \\ \text { Rules available? } & & \end{array}$


Table 1 Summary of how alignment was assessed (Continued)

\begin{tabular}{|c|c|c|c|c|c|}
\hline \multirow{4}{*}{\multicolumn{2}{|c|}{1 A global system must produce data that can }} & \multicolumn{2}{|l|}{.96} & \multicolumn{2}{|l|}{ As below } \\
\hline & & & IP vs AP? & Yes & Weak \\
\hline & & & \% "other" & Max $<20 \%$ & Weak \\
\hline & & & National? & Yes & Weak \\
\hline \multirow{3}{*}{\multicolumn{2}{|c|}{$\begin{array}{l}\text { A global system must require neonatal } \\
\text { deaths to be clearly distinguished from } \\
\text { stillbirths }\end{array}$}} & .94 & & $\begin{array}{l}\text { Yes for both } \\
\text { variables below }\end{array}$ & \\
\hline & & & Distinguishes SB and NND? & & Strong \\
\hline & & & $\begin{array}{l}\text { Separate categories for SB } \\
\text { and NND? }\end{array}$ & & Strong \\
\hline 3 & $\begin{array}{l}\text { A global system must have high inter- and } \\
\text { intra-rater reliability }\end{array}$ & .94 & Reliability testing? & Yes; $\min \geq 0.60$ & Strong \\
\hline \multirow{3}{*}{\multicolumn{2}{|c|}{$\begin{array}{l}\text { A global system must be available in } \\
\text { different formats including inexpensive } \\
\text { ehealth and mhealth options, and in } \\
\text { multiple languages }\end{array}$}} & .92 & & $\begin{array}{l}\text { Yes for both } \\
\text { variables below }\end{array}$ & \\
\hline & & & E-format? & & Strong \\
\hline & & & $>1$ language? & & Weak \\
\hline 5 & $\begin{array}{l}\text { A global system must allow easy access to } \\
\text { the data by the end-users }\end{array}$ & .92 & Accessible data? & Yes & Weak \\
\hline 6 & $\begin{array}{l}\text { A global system must incorporate both } \\
\text { stillbirths and neonatal deaths }\end{array}$ & .86 & Both SB and NND? & Yes & Strong \\
\hline \multirow{4}{*}{\multicolumn{2}{|c|}{$\begin{array}{l}\text { A global system must require the single } \\
\text { most important factor leading to the death } \\
\text { to be recorded }\end{array}$}} & .86 & & As below & \\
\hline & & & Hierarchical? & No or partially & Weak \\
\hline & & & Only 1 cause allowed? & Yes & Strong \\
\hline & & & Includes FGR/IUGR/SGA? & No & Strong \\
\hline
\end{tabular}

("weak" variables). For example, the variable recording the number of categories at the highest level of a system was judged to be particularly robust ("strong") in measuring characteristic 7 , which calls for systems to have a small number of main categories, as data extraction was straightforward. On the other hand, the variable recording whether a system was available in more than one language was judged to be less robust ("weak") in measuring characteristic 14, since it was possible that we had missed systems in languages not commonly found in the databases searched for the systematic literature review. The maximum possible unweighted and weighted scores using "strong" variables only were 12 and 11, respectively.

Subgroup analyses were undertaken to explore differences in alignment according to: (i) type of death included (SB only, NND only, or both); (ii) systems that were widely vs less used (a widely used system was defined as any system used to classify 1000 or more deaths and/or used in two or more countries between 2009 and 2014; details presented in [3]); (iii) region of use according to World Bank country classification (HIC vs LMIC)
[8]; and (iv) type of characteristic (functional vs structural). For the type of characteristic, mean unweighted scores for alignment of all systems with functional and structural characteristics were calculated (with maximum possible scores of 9 and 8, respectively).

Data were entered into in Stata/IC 12.1 for analysis of frequency distributions. System developers who are co-authors were excluded from data extraction and analysis.

\section{Results}

\section{Overall alignment}

The range of unweighted scores for system alignment with the 17 expert-identified characteristics for an effective global system was 0 to 9 out of a maximum possible score of 17 , meaning that none of the 81 systems was aligned with more than 9 of these characteristics (see Table 2). Most systems (82\%) were aligned with four or fewer characteristics. The range of weighted scores for system alignment with the characteristics was 0 to 7.94 out of a maximum 
Table 2 Weighted and unweighted scores measuring system alignment against expert-identified characteristics

\begin{tabular}{|c|c|c|c|c|}
\hline & Score using a & & Score using " & les only \\
\hline & Unweighted & Weighted & Unweighted & Weighted \\
\hline Maximum possible score & 17 & 15.64 & 12 & 11.00 \\
\hline Froen 2009-Codac [9] & 9 & 7.94 & 8 & 7.14 \\
\hline Korteweg 2006-Tulip [10] & 7 & 6.20 & 6 & 5.40 \\
\hline Black 2010-CHERG [11] & 6 & 5.50 & 3 & 2.82 \\
\hline Cole 1986 [12] & 6 & 5.48 & 5 & 4.52 \\
\hline Flenady 2009-PSANZ-PDC [13] & 6 & 5.50 & 5 & 4.54 \\
\hline Kotecha 2014-Wales [14] & 6 & 5.42 & 4 & 3.70 \\
\hline Ujwala 2012 [15] & 6 & 5.18 & 5 & 4.38 \\
\hline Chan 2004-PSANZ-NDC [23] & 5 & 4.46 & 4 & 3.66 \\
\hline Kidanto 2009 [24] & 5 & 4.38 & 5 & 4.38 \\
\hline Lawn 2006-CHERG [25] & 5 & 4.72 & 4 & 3.82 \\
\hline Manning 2013-maternal \& fetal-Ireland [26] & 5 & 4.52 & 4 & 3.60 \\
\hline Pattinson 1989 [27] & 5 & 4.58 & 4 & 3.78 \\
\hline Schmiegelow 2012 [28] & 5 & 4.42 & 5 & 4.42 \\
\hline Varli 2008-Stockholm [29] & 5 & 4.58 & 4 & 3.78 \\
\hline Wigglesworth 1980 [30] & 5 & 4.46 & 3 & 2.70 \\
\hline Abdellatif 2013 [31] & 4 & 3.34 & 3 & 2.54 \\
\hline CMACE 2010-maternal \& fetal [32] & 4 & 3.60 & 4 & 3.60 \\
\hline CMACE 2010-neonatal [32] & 4 & 3.46 & 3 & 2.66 \\
\hline de Galan-Roosen 2002 [16] & 4 & 3.48 & 4 & 3.48 \\
\hline Engmann 2012 [33] & 4 & 3.46 & 3 & 2.66 \\
\hline Flenady 2009-PSANZ-NDC [13] & 4 & 3.58 & 3 & 2.78 \\
\hline Gardosi 2014-MAIN ${ }^{a}$ & 4 & 3.52 & 4 & 3.52 \\
\hline Gordijn 2009 [18] & 4 & 3.68 & 4 & 3.68 \\
\hline Khanum 2009 [34] & 4 & 3.42 & 3 & 2.62 \\
\hline Kidron 2009 [35] & 4 & 3.78 & 4 & 3.78 \\
\hline McClure $2015[42]^{\mathrm{b}}$ & 4 & 3.74 & 5 & 4.60 \\
\hline Mo-Suwan 2009 [36] & 4 & 3.52 & 4 & 3.52 \\
\hline MRC 2002-PPIP-South Africa [37] & 4 & 3.52 & 3 & 2.72 \\
\hline National Services Scotland 2013-neonatal [38] & 4 & 3.40 & 2 & 1.68 \\
\hline NIPORT 2005-Bangladesh [39] & 4 & 3.70 & 2 & 1.98 \\
\hline Shah 2011 [40] & 4 & 3.60 & 4 & 3.66 \\
\hline Van Diem 2010 [41] & 4 & 3.46 & 3 & 2.66 \\
\hline VanderWielen 2011-WiSSP [42] & 4 & 3.60 & 4 & 3.60 \\
\hline Wood 2012 [43] & 4 & 3.44 & 4 & 3.44 \\
\hline Basys 2014-Lithuania [44] & 3 & 2.58 & 3 & 2.58 \\
\hline Chan 2004-PSANZ-PDC [23] & 3 & 2.84 & 3 & 2.84 \\
\hline CMACE 2011-maternal \& fetal [45] & 3 & 2.62 & 3 & 2.62 \\
\hline Cole 1989-ICE [46] & 3 & 2.84 & 3 & 2.84 \\
\hline De Reu 2009-Tulip mod. [47] & 3 & 2.52 & 2 & 1.72 \\
\hline Froen 2009-simplified Codac [9] & 3 & 2.54 & 3 & 2.54 \\
\hline Gardosi 2005-ReCoDe [48] & 3 & 2.76 & 2 & 1.80 \\
\hline Glinianaia 2010 [49] & 3 & 2.52 & 2 & 1.72 \\
\hline
\end{tabular}


Table 2 Weighted and unweighted scores measuring system alignment against expert-identified characteristics (Continued)

\begin{tabular}{|c|c|c|c|c|}
\hline Hey 1986 [50] & 3 & 2.84 & 4 & 3.70 \\
\hline Hinderaker 2003 [51] & 3 & 2.52 & 2 & 1.72 \\
\hline Manandhar 2010 [52] & 3 & 2.70 & 4 & 3.56 \\
\hline National Services Scotland 2013-obstetric [38] & 3 & 2.64 & 2 & 1.72 \\
\hline Nausheen 2013 [53] & 3 & 2.88 & 4 & 3.74 \\
\hline Nga 2012 [54] & 3 & 2.60 & 3 & 2.66 \\
\hline SCRN WG 2011 [55] & 3 & 2.70 & 3 & 2.70 \\
\hline Simpson 2010 [56] & 3 & 2.48 & 2 & 1.68 \\
\hline Abha 2011 [57] & 2 & 1.68 & 2 & 1.68 \\
\hline Aggarwal 2011 [58] & 2 & 1.78 & 1 & 0.98 \\
\hline Aggarwal 2013 [59] & 2 & 1.74 & 1 & 0.94 \\
\hline Black-2010-CHERG [11] & 2 & 1.68 & 2 & 1.68 \\
\hline De Reu 2009-Cole mod. [47] & 2 & 1.66 & 2 & 1.72 \\
\hline De Reu 2009-Wigglesworth mod. [47] & 2 & 1.66 & 2 & 1.72 \\
\hline Dias e Silva 2013 [60] & 2 & 1.68 & 2 & 1.68 \\
\hline Dudley 2010-INCODE [61] & 2 & 1.80 & 3 & 2.72 \\
\hline Hey 1986-short form [50] & 2 & 1.66 & 2 & 1.72 \\
\hline Khanal 2011 [62] & 2 & 1.66 & 1 & 0.86 \\
\hline Lawn 2009-consistent classification for causes of stillbirth [63] & 2 & 1.88 & 2 & 1.88 \\
\hline Lawn 2010 [36] & 2 & 1.82 & 1 & 0.86 \\
\hline Lawn 2012 [64] & 2 & 1.82 & 1 & 0.86 \\
\hline National Services Scotland 2013-FIGO [38] & 2 & 1.72 & 2 & 1.72 \\
\hline Olamijulo 2011 [65] & 2 & 1.72 & 2 & 1.72 \\
\hline Seaton 2012 [66] & 2 & 1.66 & 1 & 0.86 \\
\hline Serena 2013-Wigglesworth mod. [67] & 2 & 1.66 & 1 & 0.86 \\
\hline Winbo 1998-NICE [68] & 2 & 1.66 & 2 & 1.72 \\
\hline Winter 2013-Rwanda [69] & 2 & 1.66 & 1 & 0.86 \\
\hline Cunningham ${ }^{d} 1997[70]$ & 1 & 0.82 & 1 & 0.82 \\
\hline Freitas 2012 [71] & 1 & 0.86 & 1 & 0.86 \\
\hline Gupta 2012-Bhutan [72] & 1 & 0.80 & 0 & 0.00 \\
\hline Hama Diallo 2012 [73] & 1 & 0.82 & 1 & 0.82 \\
\hline Jehan $2009^{e}[74]$ & 1 & 0.80 & 0 & 0.00 \\
\hline Kruse 2014 [75] & 1 & 0.80 & 1 & 0.86 \\
\hline Nabeel 2012 [76] & 1 & 0.82 & 2 & 1.68 \\
\hline Public Health Agency of Canada 2008 [77] & 1 & 0.86 & 1 & 0.86 \\
\hline Rocha 201178 & 1 & 0.82 & 1 & 0.82 \\
\hline Smith 2010 [79] & 1 & 0.80 & 1 & 0.86 \\
\hline Serena 2013-ReCoDe mod. [67] & 0 & 0.00 & 0 & 0.00 \\
\hline Wou 2014 [80] & 0 & 0.00 & 0 & 0.00 \\
\hline
\end{tabular}

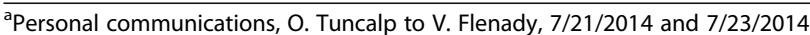

${ }^{\mathrm{b}}$ System was included via expert referral in 2014 and this paper was selected as the citation after its publication in 2015

'Two modifications of CHERG in Black 2010; this is found in his Webappendix 2

${ }^{d}$ System is described in the reference given, but originates from [81]

epubMed citation is for Imtiaz; we use the family name Jehan to refer to this system 
Table 3 System alignment with expert-identified characteristics for an effective global classification system for causes of stillbirth and neonatal death

\begin{tabular}{|c|c|c|c|c|c|c|c|c|c|}
\hline \multirow[t]{2}{*}{ Characteristics } & \multirow[t]{2}{*}{$\%$ consensus } & \multicolumn{8}{|c|}{$\%$ systems in alignment with each characteristic } \\
\hline & & All (81) & $\begin{array}{l}\text { Widely } \\
\text { used }^{\mathrm{a}}(27)\end{array}$ & $\begin{array}{l}\text { Less } \\
\text { used (54) }\end{array}$ & $\begin{array}{l}\text { Used in HIC } \\
\text { only (36) }\end{array}$ & $\begin{array}{l}\text { Used in LMIC } \\
\text { only (32) }\end{array}$ & $\begin{array}{l}\text { SB-only } \\
\text { systems (15) }\end{array}$ & $\begin{array}{l}\text { NND-only } \\
\text { systems (26) }\end{array}$ & $\begin{array}{l}\text { Combined } \\
\text { systems (NND } \\
\text { and SB) (40) }\end{array}$ \\
\hline
\end{tabular}

\section{Structural}

1 A global system must use $98 \%$ rules to ensure valid assignment of cause of death categories.

2 A global system must be $98 \%$ able to work with all

levels of data (from both low-income and high-income countries), including minimal levels.

3 A global system must ensure cause of death categories are relevant in all settings.

4 A global system must require associated factors to be recorded and clearly distinguished from causes of death.

5 A global system must distinguish between antepartum and intrapartum conditions.

6 A global system should record the level of data available to assign the cause of death (e.g. verbal autopsy only, placental histology, autopsy, etc.).

7 A global system must have multiple levels of causes of death, with a small number of main categories.

8 A global system must include a sufficiently comprehensive list of categories to result in a low proportion of deaths classified as "other".

Functional

9 A global system must be easy to use, and produce data that are easily understood and valued by users.

10 A global system must have clear guidelines for use and definitions for all terms used.

11 A global system must produce data that can be used to inform strategies to prevent perinatal deaths.

$96 \%$

$94 \%$

$90 \%$

$86 \%$

$80 \%$

$96 \%$

$\begin{array}{lllllll}41 \% & 52 \% & 35 \% & 44 \% & 28 \% & 53 \% & 35 \%\end{array}$

$3 \% \quad 7 \% \quad 0 \% \quad 0 \%$

$0 \%$

$0 \%$

$8 \%$

$0 \%$

$10 \% \quad 30 \%$

$0 \%$

$0 \%$

$0 \%$

$7 \%$

$15 \%$

$8 \%$

$14 \% \quad 19 \%$

$11 \%$

$17 \%$

$13 \%$

$7 \%$

$8 \%$

$20 \%$

$20 \% \quad 19 \%$

$20 \%$

$22 \%$

$16 \%$

$20 \%$

$0 \%$

$33 \%$

$9 \% \quad 19 \%$

$4 \%$

$19 \%$

$0 \%$

$7 \%$

$4 \%$

$13 \%$

$43 \%$

$33 \%$

$44 \%$

$33 \%$

$42 \%$

$40 \%$

$48 \% \quad 52 \%$

$46 \%$

$53 \%$

$53 \%$

$27 \%$

$65 \%$

$45 \%$

$100 \%$

$0 \% \quad 0 \%$

$0 \%$

$0 \%$

$0 \%$

$0 \%$

$0 \%$

$0 \%$

$100 \%$

$17 \% \quad 15 \%$

$19 \%$

$17 \%$

$16 \%$

$20 \%$

$19 \%$

$15 \%$

$0 \% \quad 0 \%$

$0 \%$

$0 \%$

$0 \%$

$0 \%$

$0 \%$

$0 \%$ 
Table 3 System alignment with expert-identified characteristics for an effective global classification system for causes of stillbirth and neonatal death (Continued)

\begin{tabular}{|c|c|c|c|c|c|c|c|c|c|c|}
\hline 12 & $\begin{array}{l}\text { A global system must } \\
\text { require neonatal deaths } \\
\text { to be clearly distinguished } \\
\text { from stillbirths. }\end{array}$ & $94 \%$ & $5 \%$ & $7 \%$ & $4 \%$ & $0 \%$ & $9 \%$ & $0 \%$ & $0 \%$ & $10 \%$ \\
\hline 13 & $\begin{array}{l}\text { A global system must } \\
\text { have high inter- and } \\
\text { intra-rater reliability. }\end{array}$ & $94 \%$ & $7 \%$ & $11 \%$ & $6 \%$ & $8 \%$ & $6 \%$ & $7 \%$ & $0 \%$ & $13 \%$ \\
\hline 14 & $\begin{array}{l}\text { A global system must be } \\
\text { available in different } \\
\text { formats including } \\
\text { inexpensive ehealth and } \\
\text { mhealth options, and in } \\
\text { multiple languages. }\end{array}$ & $92 \%$ & $0 \%$ & $0 \%$ & $0 \%$ & $0 \%$ & $0 \%$ & $0 \%$ & $0 \%$ & $0 \%$ \\
\hline 15 & $\begin{array}{l}\text { A global system must } \\
\text { allow easy access to the } \\
\text { data by the end-users. }\end{array}$ & $92 \%$ & $10 \%$ & $11 \%$ & $9 \%$ & $14 \%$ & $6 \%$ & $0 \%$ & $12 \%$ & $13 \%$ \\
\hline 16 & $\begin{array}{l}\text { A global system must } \\
\text { incorporate both stillbirths } \\
\text { and neonatal deaths. }\end{array}$ & $86 \%$ & $49 \%$ & $48 \%$ & $50 \%$ & $56 \%$ & $44 \%$ & $0 \%$ & $0 \%$ & $100 \%$ \\
\hline 17 & $\begin{array}{l}\text { A global system must } \\
\text { require the single most } \\
\text { important factor leading } \\
\text { to the death to be } \\
\text { recorded. }\end{array}$ & $86 \%$ & $47 \%$ & $52 \%$ & $44 \%$ & $50 \%$ & $41 \%$ & $33 \%$ & $50 \%$ & $50 \%$ \\
\hline
\end{tabular}

"Widely used": systems used in more than one country and/or to classify 1000 or more deaths

possible score of 15.64 ; by this measure, systems were aligned with $19 \%$ of characteristics on average (equivalent to an average weighted score of 2.82).

The most aligned of the 81 systems was Frøen 2009Codac [9], with an unweighted score of 9 and a weighted score of 7.94. The next most aligned system was Korteweg 2006-Tulip [10], with an unweighted score of 7 and a weighted score of 6.20 .
Five systems were next most aligned with the 17 expertidentified characteristics, according to both unweighted and weighted scores. These were Black 2010-CHERG [11], Cole 1986 [12], Flenady 2009-PSANZ-PDC [13], Kotecha 2014Wales [14], and Ujwala 2012 [15]. All were aligned with 6 out of the 17 characteristics (i.e., an unweighted score of 6); they had weighted scores of 5.50, 5.48, 5.50, 5.42, and 5.18, respectively.

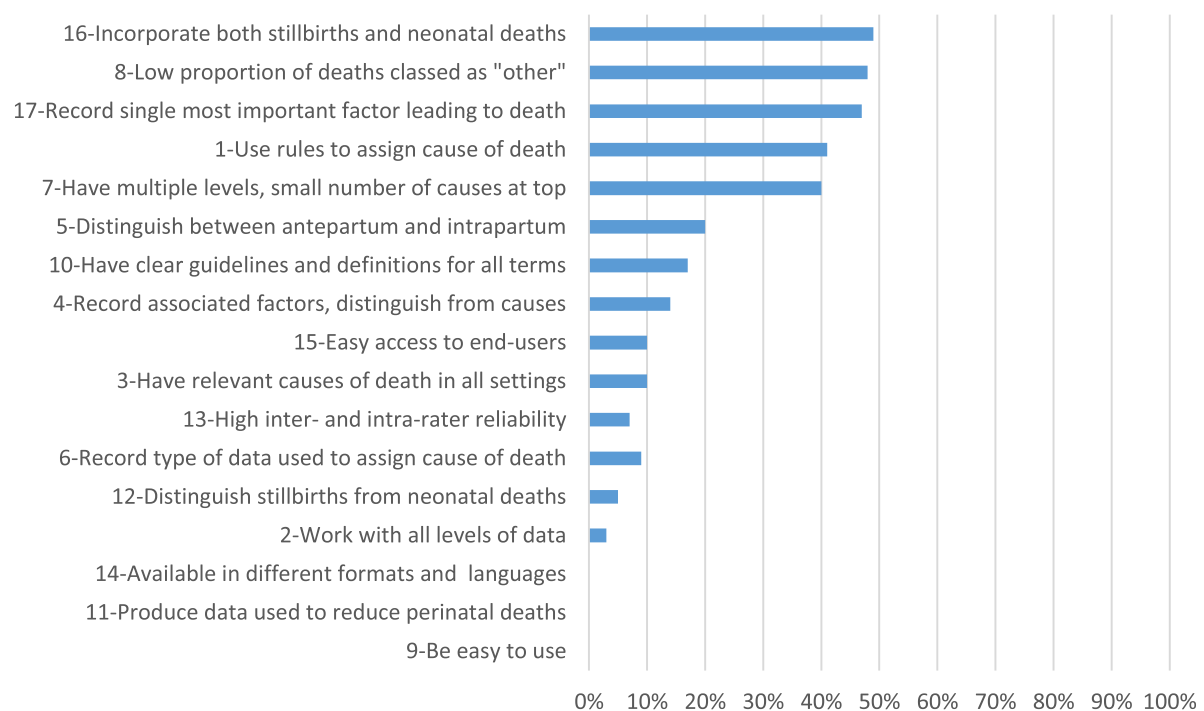

Fig. 1 Percent of systems aligned with expert-identified characteristics for an effective global system. Note: Numbers in front of characteristics refer to sequence of characteristics in Table 1 
This group of seven most aligned systems included one global system and two national systems (used in Australia, New Zealand, and Wales). All but one (Black 2010-CHERG) were used for classifying both SB and NND. All but one (Cole 1986) were developed from 2006 onward. All but Kotecha 2014-Wales and Ujwala 2012 were "widely used" by our definition.

\section{Characteristics with greatest and least alignment}

System alignment with individual characteristics ranged from 0 to 49 \% (see Table 3 and Fig. 1 for details). There were only five characteristics with which systems were highly aligned (i.e., $40 \%$ or more systems aligned): (1) forty systems (49\%) were aligned with the requirement to incorporate both stillbirths and neonatal deaths, with LMIC-only systems somewhat less aligned than HIConly systems (44\% v $56 \%$ ); (ii) just under half the systems were aligned with the requirement to produce a low proportion of deaths classified as "other", with alignment particularly high for the NND-only systems as compared to the SB-only systems (65 \% v $27 \%$ ); (iii) also just under half the systems were aligned with the requirement to record the single most important factor leading to death, with alignment of SB-only systems somewhat lower than for NND-only systems (33 \% v $50 \%$ ); (iv) thirty-three systems (41\%) were aligned with the requirement to use rules for valid assignment of cause of death, a feature that was more common among widely used than less used systems (52\% v $35 \%)$, HIC-only than LMIC-only systems (44\% v $28 \%)$, and SB-only than NND-only systems (53\% v $35 \%$ ); and (v) thirty-two systems (40\%) were aligned with the requirement to have multiple levels and a small number of causes at the top level.

Alignment was $10 \%$ or lower for nine characteristics: (i) just eight of the 81 systems $(10 \%)$ were aligned with the requirement that systems use categories that are "relevant in all settings" (the exact characteristic is "A global system must ensure cause of death categories are relevant in all settings"), including 8 of the 27 widely used systems (30\%) and 4 of the 26 NND-only systems (15\%); (ii) eight systems were aligned with the requirement to allow end-users easy access to the data, including five of the $36 \mathrm{HIC}$-only systems and three of the 26 NND-only systems; (iii) seven systems (9\%) were aligned with the requirement to record the type of data used to assign cause of death, including seven of the 36 systems used only in HIC (19 \%); (iv) six systems (7 \%) were aligned with the requirement that systems have high reliability, including five of the 40 systems classifying both SB and NND; (v) four systems (5\%) were aligned with the requirement that systems distinguish NND from SB; (vi) two systems were aligned with the requirement that systems be able to work with data from LMIC as well as
HIC settings; and (vii) no systems were aligned with the requirements that systems produce data that can be used to inform strategies to prevent death, be easy to use and produce easily understood data, and be accessible (available online and in multiple languages).

\section{Subgroup analyses \\ Alignment according to type of death classified}

Alignment according to type of death classified (SB only, NND only, or both) was broadly similar to overall alignment (see Table 3). The 26 NND-only systems had an average unweighted score of 2.58 , meaning they were aligned with an average of $15 \%$ of the 17 characteristics; the 15 SB-only systems were aligned with $13 \%$ of the 17 characteristics on average, and the 40 combined systems with $23 \%$ (data not shown).

Alignment with the eight structural characteristics was generally similar for SB-only, NND-only and combined (SB and NND) systems, but different for the nine functional characteristics, with the 15 SB-only systems having an average unweighted score of just 0.60 (meaning they were aligned with just 0.60 of these characteristics on average) and the $26 \mathrm{NND}$-only systems aligned with just 0.81 , whereas the 40 combined systems were aligned with 2.00 of these characteristics on average.

Alignment with individual characteristics also varied somewhat according to type of death classified. Other than characteristics requiring certain types of deaths to be included (e.g. the one requiring intrapartum and antepartm SB to be distinguished), alignment varied most strongly for the characteristic which requires systems to have a low proportion of deaths classified as "other": four out of the 15 SB-only systems, or $27 \%$, and 17 out of the 26 NND-only systems, or $65 \%$, were aligned. Systems including both types of death were more aligned with the requirement to include associated factors $(20 \%$, v $7 \%$ for SB-only systems and $8 \%$ for NND-only systems). NND-only systems were least aligned with the requirement to use rules for assigning cause of death (35\%, v $40 \%$ for combined systems and $53 \%$ for SB-only systems), while NND-only and combined systems were both more aligned with the requirement to record the single most important factor leading to death $-50 \%$, as opposed to $33 \%$ for SB-only systems.

\section{Alignment of widely used systems}

The 27 widely used systems were somewhat more aligned than the 54 less used systems with all 17 characteristics, with an average unweighted score of 3.74 (aligned with an average of $22 \%$ of the characteristics) as compared to 2.91 (aligned with an average of $17 \%$ ). Widely used systems were also more aligned with the eight structural characteristics than less used systems, with an average unweighted score of 2.30 as compared 
to 1.59; the main differences related to characteristics requiring rules for use, globally relevant categories, and recording of the type of data used to assign cause of death. Widely and less used systems were similar in terms of alignment with the nine functional characteristics.

\section{Alignment by region of use}

Systems used only in HIC and only in LMIC had generally similar alignment with the 17 characteristics (with average unweighted scores of 3.33 and 2.75 , representing $20 \%$ and $16 \%$ of the maximum possible score, respectively). Alignment was also similar for structural and functional characteristics considered separately, though HIC-only systems were slightly more aligned within each group: HIC-only systems were aligned with $24 \%$ of the eight structural characteristics and $16 \%$ of the nine functional characteristics; the figures for LMIC-only systems were $19 \%$ and $14 \%$, respectively. Systems used only in HIC were more aligned with the characteristics requiring systems to use rules to assign cause of death and to record the type of data used to assign cause of death.

\section{Alignment by type of characteristic}

On average, systems had a mean unweighted score of 1.83 for alignment with the eight characteristics assessing systems' structure (equivalent to alignment with $23 \%$ of these characteristics) and 1.36 of the nine characteristics assessing systems' functioning (equivalent to alignment with $15 \%$ of these characteristics).

\section{Sensitivity analysis}

The results of sensitivity analyses (see Methods and Additional file 3 for details) show that Frøen 2009Codac remained the most-aligned system even when restricting the alignment assessment to only the "strong" variables, with an unweighted score of 8 out of a maximum possible score of 12 (meaning that it was aligned with $67 \%$ of characteristics measured by "strong" variables), and a weighted score of 7.14 out of a maximum possible 11 (aligned with $65 \%$ of characteristics measured by "strong" variables when weighting was applied). Similarly, Korteweg 2006-Tulip remained the second-mostaligned system even with the restricted analysis, with an unweighted score of 6 and a weighted score of 5.40.

Three other systems were also among the highest scoring independently of whether weaker variables were included or not: Cole 1986, Flenady 2009-PSANZ-PDC, and Ujwala 2012, with unweighted scores using only "strong" variables of 5 for each of these systems, and weighted scores of 4.52, 4.54, and 4.38, respectively.

Results of sensitivity testing for different cut-offs for quantitative variables used to assess alignment with characteristics 7, 8 and 13 showed that the number of aligned systems was not very sensitive to the cut-offs assessed (see Table 1 for list of characteristics and Additional file 3 for details).

\section{Discussion}

This study is the first to apply characteristics for an effective global classification system, as identified by an external panel of experts, to a set of classification systems for causes of SB and NND that were identified through a comprehensive, systematic literature review without language limits, and which included modifications as well as new systems. We found that classification systems for causes of stillbirth and neonatal death were overall poorly aligned with expert-identified characteristics; no system was aligned with more than 9 of 17 characteristics. This lack of alignment of current systems with the characteristics of an "ideal" classification system for causes of perinatal death may contribute to the ongoing development of new and modified systems at the rate of ten a year for the previous five years, possibly hindering the potential for widespread acceptance of one classification system.

Several researchers have previously assessed classification systems against various characteristics for an effective system. De Galan-Roosen 2002 assessed 12 systems, including four included in our study (the Wigglesworth 1980, Cole 1986, Hey 1986, and de Galan-Roosen 2002 itself), against seven characteristics, four of which are similar to our expert-identified characteristics (reliability, explanation of underlying cause, inclusion of both $\mathrm{SB}$ and NND, and the percent of "unclassifiable" deaths) [16]. Flenady 2009 assessed six systems, five of which are included in our study (Cole 1986, Flenady 2009-PSANZPDC, Gardosi 2005-ReCoDe, Korteweg 2006-Tulip and Frøen 2009-Codac) against three characteristics, two of which are included among our expert-identified characteristics (ease of use and reliability) [82]. Frøen 2009 assessed 11 systems, at least six of which were included in our study (versions of Aberdeen and Pattinson were also included but the version is unknown), against seven characteristics, four of which are included among our expert-identified characteristics (number of categories per level, whether underlying cause is identified, what type of data are required for use, and reliability) [17]. The previous most comprehensive review we are aware of, Gordijn, assessed 35 systems, of which we have included 12, against six characteristics, only one of which is included among the expert characteristics (number of causes per level) [18].

De Galan [16] found that their own system was most in alignment with the characteristics they considered, followed by the Hovatta system [19]; Flenady 2009 found that Frøen 2009-Codac, Flenady 2009-PSANZ-PDC and Gardosi 2005-ReCoDe performed best overall; and Frøen 2009 found that Flenady 2009-PSANZ-PDC and Frøen 
2009-Codac were most in compliance with the characteristics reviewed, while Korteweg 2006-Tulip would require only modest modification (a new category for intrapartum) to become compliant. Gordijn stated that "each system [reviewed] has its own strengths and weaknesses", and proposed combining existing systems to capitalize on their strengths so as to produce a new approach that would be well-aligned with key characteristics for an effective system.

A major difference between this study and prior reviews was our approach of assessing overall alignment of a comprehensively identified set of systems using a weighted scoring system against characteristics developed transparently by an external panel of experts. Despite this difference, we also identified Frøen 2009-Codac as the most aligned with expert characteristics for an effective global system, according to both unweighted and weighted scoring and regardless of whether we included only "strong" variables in the assessment or not. Four other systems were also consistently identified as among the most-aligned regardless of the scoring approach: Korteweg 2006-Tulip, which was consistently the second-most-aligned system, and Flenady 2009PSANZ-PDC, Cole 1986, and Ujwala 2012. These results are similar to the findings of the Flenady and Frøen reviews $[17,82]$.

The concordance of these reviews may indicate underlying strengths of these systems, but must also be regarded in light of our finding of poor alignment even among the most aligned systems. We therefore suggest that rather than "best" systems, we have instead identified the most-aligned of a group that still lacks some essential features needed for effective global use. For instance, Frøen 2009-Codac, which we found to be the most-aligned system, and which was recently adopted by the UK for use in its national perinatal mortality surveillance, has shown a high proportion of stillbirths classified with "unknown" as the primary cause of death (47\% and $46 \%$ from the first two annual reports in 2013 and 2014, respectively) [20,21]. This high rate of "unknown" stillbirths using Codac in a high-income country has occurred despite education and training for the designated hospital-based staff who submit the data. However, disaggregation of the data (as the "unknown" category in Codac includes subcategories of both "unexplained" deaths despite thorough investigation, and "unknown" deaths with insufficient investigation or documentation) could help indicate the need for improved investigation of stillbirths as well as areas in need of strengthening within the system itself.

This example highlights the fact that while education and training for system implementation are necessary, they may not be sufficient to classify causes of perinatal death adequately. There remains a need for a system that is fully aligned with expert-identified characteristics for an effective global solution, notably including alignment with characteristics calling for the ability to work with all levels of data, from both HIC and LMIC settings, "ease of use", and the production of data that "can be used to inform strategies to prevent perinatal death".

It might be expected that a globally effective system would be aligned with the characteristics we found to have highest alignment among identified systems-hence, that it would provide rules for use, have multiple levels and a small number of categories at the top level, produce no more than $20 \%$ of deaths classified as "other", include both SB and NND, and record the single most important factor leading to death. Such a system would stand out from existing systems for also being aligned with the characteristics we found to have lowest alignment overall, in particular, the three characteristics absent from all systems (that systems should be easy to use and produce easily understandable data, produce data that can be used to inform strategies to prevent perinatal death, and be available in ehealth and mhealth options and in multiple languages). Having these features would strongly distinguish any new system from the rest.

Development of a globally effective system may also benefit from reference to systems that we identified as more aligned, despite their low alignment ratings overall. For instance, Frøen 2009-Codac was alone among the more aligned systems in providing a link for users to access data that are produced by the system. There are seven other systems we found which provide this access, one global and all the rest national systems. It may also be of interest to examine the characteristics of the national systems we found that are more aligned. In addition to being used nationally, these two systems (Kotecha 2014-Wales and Flenady 2009-PSANZ-PDC) were both aligned with two characteristics: they provided rules for use, and they included both SB and NND. A globally effective system might therefore stand apart from the large number of existing systems if it also bore these characteristics.

That combined systems (those incorporating both SB and NND) were somewhat more aligned than SB-only and NND-only systems may be a reflection of the weight placed upon this feature within the assessment methodology, with two characteristics dependent upon it (requiring SB to be distinguished from NND, and requiring inclusion of both types of death). An effective global system must incorporate both SB and NND. Given the somewhat greater alignment of the 27 widely used systems, it may also be of interest to note key features of these, which included identification of the single most important factor leading to death, greater availability of rules for use, definitions for some or all causes of death, and allowing associated factors to be recorded [3]. The 
slightly higher alignment of systems used only in HIC as compared to only in LMIC could point to a need for particularly careful implementation of a system intended to be globally effective, in order to identify and address any differences in functioning, acceptance, access, or interpretation across settings.

Given the finding of overall lower alignment with functional as compared to structural characteristics, attention should also be paid to ensuring a new system exhibits some of the key functional characteristics, including reliability (systems scored low on this more due to the lack of any reliability testing than to low Kappa scores) and accessibility (systems scored low on this due to lack of availability online and in multiple languages).

Another approach that may be of use to policy makers and public health officials in low-resource settings seeking to apply the results of this research would be to prioritize the characteristics and work toward alignment of their classification systems to the higher-priority ones first. During the process of identifying characteristics [7], panellists were not asked to rank them, rather, to indicate their level of agreement that a given characteristic was important for a globally effective system. Hence, each characteristic was judged on its own merit, not in conjunction with other characteristics. With an agreed cut-off of $80 \%$ of more panellists stating "agree" or "strongly agree" with the characteristic's importance for a globally effective system, 17 characteristics were ultimately selected. The percent agreement (shown in Table 1 as the weights for each characteristic) could be taken as a rough proxy for rank. The differences between characteristics are necessarily not very pronounced, since all had at least $80 \%$ agreement. Yet still, some were less strongly supported than others. There are six characteristics with $96 \%$ agreement or more, which could be a starting point for lower-resourced settings:

- A global system must be easy to use, and produce data that are easily understood and valued by users (agreed by $100 \%$ of panellists)

- A global system must have clear guidelines for use and definitions for all terms used (agreed by $100 \%$ of panellists)

- A global system must use rules to ensure valid assignment of cause of death categories (agreed by $98 \%$ of panellists)

- A global system must be able to work with all levels of data (from both low-income and high-income countries), including minimal levels (agreed by $98 \%$ of panellists)

- A global system must ensure cause of death categories are relevant in all settings (agreed by $96 \%$ of panellists)

- A global system must produce data that can be used to inform strategies to prevent perinatal deaths (agreed by $96 \%$ of panellists)
This study had some limitations. There was not a one-toone correspondence between characteristics and the variables meant to measure these characteristics, and we relied on information available in published reports, which often lacked the detail required to measure characteristics precisely. This, along with the inherently more subjective nature of some characteristics (for instance, the characteristic requiring systems to produce data "that can be used to inform strategies to prevent perinatal deaths"), meant that some characteristics were found to be measured less accurately (designated as "weak" variables in Additional file 2) than others. However, the sensitivity analysis which excluded all "weak" variables from the assessment of alignment produced a similar list of most-aligned systems, indicating the methodology was not particularly sensitive to variables' "strength".

The number of deaths classified by national systems may have been underestimated due to retaining only the most recent paper between 2009 and 2014 that described a national system. This would have affected the assessment of alignment with the characteristic requiring systems to be easy to use and produce easily understandable data, as this relied in part on the number of deaths classified. However, this is unlikely to have affected overall results, as four other variables were also incorporated into the assessment of alignment for this characteristic (which was found to be $0 \%$ for all systems).

The list of expert-identified characteristics did not include two characteristics relevant to the ICD-PM, namely whether ICD codes were used and whether both a maternal and a fetal/neonatal condition are required [22]. Both these characteristics were considered by the expert panel but ultimately did not receive $80 \%$ or greater consensus [7]. However, the characteristic requiring systems to record associated factors and distinguish them clearly from causes of death may overlap with the concept of inclusion of both maternal and fetal/neonatal conditions. Data on this characteristic and the use of ICD codes are described in Leisher et al. 2016 in this series [3].

"Hierarchy", meaning a set of rules forcing causes to be selected or rejected in a pre-determined order, was not included among the expert-identified characteristics. This is a common feature of systems (nearly one-third of systems we assessed were at least partially hierarchical), and is meant to assist in consistent assignment of cause of death when multiple conditions are present. However, along with two other variables, the "hierarchical" variable was used to assess alignment with the characteristic requiring the single most important factor leading to death to be recorded, with a value of "not hierarchical" or "partially hierarchical" indicating alignment. In recognition of the fact that there was no consensus on whether a globally effective system should be hierarchical [7], this variable was judged to be "weak", and hence excluded in the sensitivity analysis. 


\section{Conclusion}

Despite the large number of classification systems recently used and/or developed (81), there remains an unmet need for a system that is aligned with expert-identified characteristics. To increase acceptance by potential users, ease of use and accessibility will be important, including availability online and in multiple languages, provision of links to data produced by the system, and education and training for potential users. A system including these features would have the potential to become the first truly globally effective classification system, making a critical contribution to the efforts of researchers, practitioners and policy makers in all countries to prevent the tragic loss of life -5.3 million stillbirths and neonatal deaths every year.

\section{Additional files}

Additional file 1: 81 included systems and selected features. (DOCX $59.8 \mathrm{~kb}$ )

Additional file 2: Variables used to assess system alignment with expert-identified characteristics for an effective global classification system for causes of stillbirth and neonatal death. (DOCX $89.1 \mathrm{~kb}$ )

Additional file 3: Sensitivity analyses. (DOCX $62.6 \mathrm{~kb})$

\section{Abbreviations}

AP: Antepartum; CHERG: Child health epidemiology reference group; CMACE: Centre for maternal and child enquiries; Codac: Causes of death and associated conditions; DHS: Demographic and health surveys; FGR: Fetal growth restriction; FIGO: International federation of gynaecology and obstetrics; HIC: High-income countries; ICD: International classification of diseases; ICD-PM: International classification of diseases for perinatal mortality; ICE: International collaborative effort; INCODE: Initial causes of fetal death; IP: Intrapartum; IUGR: Intrauterine growth restriction; LMIC: Low- and middle-income countries; MAIN: The maternal, antenatal, intrapartum \& neonatal classification system for perinatal deaths; MRC: Medical research council; NICE: Neonatal and intrauterine death classification according to etiology; NIPORT: National institute of population research and training; NND: Neonatal death; PPIP: Perinatal problem identification programme; PSANZ-NDC: Perinatal Society of Australia and New Zealand Neonatal Death Classification; PSANZ-PDC: Perinatal Society of Australia and New Zealand Perinatal Death Classification; ReCoDe: Relevant condition at death; SB: Stillbirth; SCRN WG: The stillbirth collaborative research network working group; SGA: Small for gestational age; WHO: World Health Organization; WiSSP: Wisconsin stillbirth service program

\section{Acknowledgements}

This project was initially undertaken as part of the Harmonized Reproductive Health Registries project through the Norwegian Institute of Public Health in partnership with the Mater Research Institute, Brisbane, Australia, and in collaboration with the Department of Reproductive Health and Research, WHO. Gratitude to Craig D Leisher for support and Wilder D Leisher for inspiration.

\section{Funding}

The Mater Research Institute of the University of Queensland, Australia, provided partial funding for VF, HR, AW, TZ, and SHL to undertake this study. There was no other source of funding for this study.

\section{Availability of data and materials}

Please visit: http://research.mater.org.au/getdoc/75129bba-ca95-4481-a815b143f12ec494/stillbirth-research.

\section{Authors' contributions}

VF conceptualized the study; SHL designed the study with VF; SHL carried out data extraction and analysis; SHL coordinated all aspects of the study and drafted the paper with VF; VF and AW reviewed drafts of the manuscript. All authors (SHL, ZT, HR, EA, HB, JJE, JFF, JG, SG, AMG, AEPH, FK, JL, EMM, RP, GCSS, ÖT, AMW, VF) read and approved the final manuscript.

\section{Competing interests}

$\mathrm{SHL}, \mathrm{TZ}, \mathrm{HR}$ and AW have nothing to declare. The remaining authors have been involved in the development or evaluation of existing perinatal death classification systems.

\section{Consent for publication}

Not applicable, as no individual person's data has been reported in this paper.

Ethics approval and consent to participate

Not applicable, as no individual person's data has been reported in this paper.

\section{Author details}

${ }^{1}$ Mater Research Institute, The University of Queensland (MRI-UQ), Brisbane, Australia. ${ }^{2}$ International Stillbirth Alliance, Millburn, USA. ${ }^{3}$ Department of Reproductive Health and Research including UNDP/UNFPA/UNICEF/WHO/ World Bank Special Programme of Research, Development and Research Training in Human Reproduction (HRP), World Health Organization, Geneva, Switzerland. 'School of Women's and Infants' Health, Faculty of Medicine, Dentistry and Health Sciences, University of Western Australia, Perth, Australia. ${ }^{5}$ London School of Hygiene \& Tropical Medicine, London, UK. ${ }^{6}$ University Medical Center Groningen, The University of Groningen, Groningen, The Netherlands. ${ }^{7}$ Department of International Public Health, Norwegian Institute of Public Health, Oslo, Norway. ${ }^{8}$ Center for Intervention Science for Maternal and Child Health, University of Bergen, Bergen, Norway. ${ }^{9}$ Perinatal Institute, Birmingham, UK. ${ }^{10}$ Maternal and Fetal Health Research Centre, University of Manchester, Manchester, UK. ${ }^{11}$ St. Mary's Hospital, Central Manchester University Hospitals NHS Foundation Trust, Manchester Academic Health Science Centre, Manchester, UK. ${ }^{12}$ Department of Obstetrics and Gynaecology, Martini Hospital, Groningen, The Netherlands.

${ }^{13}$ Research Triangle Institute, North Carolina, USA. ${ }^{14}$ South Africa Medical Research Council Maternal and Infant Health Care Strategies Unit, University of Pretoria, Pretoria, South Africa. ${ }^{15} \mathrm{NIHR}$ Biomedical Research Centre \& Department of Obstetrics \& Gynaecology, Cambridge University, Cambridge, UK.

Received: 2 October 2015 Accepted: 11 August 2016

Published online: 15 September 2016

\section{References}

1. You D, Hug L, Ejdemyr S, Beise J, on behalf of the United Nations Inter-agency Group for Child Mortality Estimation (UN IGME). Levels and Trends in Child Mortality Report 2015. New York: United Nations Children's Fund; 2015.

2. Lawn JE, Blencowe H, Waiswa P, Amouzou A, Mathers C, Hogan D, et al. Stillbirths: rates, risk factors, and acceleration towards 2030. Lancet. 2016;387(10018):587-603. doi:10.1016/S0140-6736(15)00837-5.

3. Leisher SH, Zheyi T, Reinebrant H, Wojcieszek AM, Korteweg F, Blencowe $H_{\text {, }}$ et al. Seeking order amidst chaos: A systematic review of classification systems for causes of stillbirth and neonatal death, 2009-2014. Ending Preventable Stillbirths Supplement. [in press at BMC Pregnancy Childbirth] 2016.

4. Flenady V. Epidemiology of fetal and neonatal death. In: Khong TY, Malcomson RDG, editors. Keeling's Fetal and Neonatal Pathology (in press). 1st ed. 2015.

5. Lawn JE, Blencowe H, Pattinson R, Cousens S, Rajesh K, Ibiebele I, et al. Stillbirths: where? When? Why? How to make the data count? Lancet. 2011;377(9775):1448-63.

6. Allanson ER, Tunçalp Ö, Gardosi J, Pattinson RC, Francis A, Vogel JP, et al. The WHO application of ICD-10 to deaths during the perinatal period (ICD-PM): results from pilot database testing in South Africa and United Kingdom. BJOG. 2016. doi:10.1111/1471-0528.14244.

7. Wojcieszek AM, Reinebrant HE, Leisher SH, Teoh Z, Frøen JF, Tunçalp O, et al. Characteristics of a global classification system for perinatal deaths: A Delphi consensus study. Ending Preventable Stillbirths Supplement. BMC Pregnancy Childbirth. 2016. in press. doi:10.1186/s12884-016-0993-X.

8. World Bank. http://data.worldbank.org/about/country-and-lendinggroups\#High_income. 2015. Accessed 23 Feb 2015.

9. Froen JF, Pinar H, Flenady V, Bahrin S, Charles A, Chauke L, et al. Causes of death and associated conditions (Codac) - a utilitarian approach to the classification of perinatal deaths. BMC Pregnancy Childbirth. 2009;9(22). doi:10.1186/1471-2393-9-22. 
10. Korteweg FJ, Gordijn SJ, Timmer A, Erwich JJ, Bergman KA, Bouman K, et al. The Tulip classification of perinatal mortality: introduction and multidisciplinary interrater agreement. BJOG. 2006;113(4):393-401. doi:10.1111/j.1471-0528.2006.00881.x.

11. Black RE, Cousens S, Johnson HL, Lawn JE, Rudan I, Bassani DG, et al. Global, regional, and national causes of child mortality in 2008: a systematic analysis. Lancet. 2010;375(9730):1969-87. doi:http://dx.doi.org/10.1016/ S0140-6736(10)60549-1.

12. Cole SK, Hey EN, Thomson AM. Classifying perinatal death: an obstetric approach. Br J Obstet Gynaecol. 1986;93(12):1204-12.

13. Flenady V, King J, Charles A, Gardener G, Ellwood D, Day K, et al. PSANZ Clinical Practice Guideline for Perinatal Mortality. 2009.

14. Kotecha S, Kotecha S, Rolfe K, Barton E, John N, Lloyd M, et al. All Wales Perinatal Survey Annual Report 2013 Cardiff, Wales. 2014.

15. Ujwala B, Alcock G, More NS, Sushmita D, Wasundhara J, Osrin D. Stillbirths and newborn deaths in slum settlements in Mumbai, India: a prospective verbal autopsy study. BMC Pregnancy Childbirth. 2012;12(39). doi:10.1186/1471-2393-12-39.

16. de Galan-Roosen AE, Kuijpers JC, van der Straaten PJ, Merkus JM. Fundamental classification of perinatal death. Validation of a new classification system of perinatal death. Eur J Obstet Gynecol Reprod Biol. 2002;103(1):30-6.

17. Froen JF, Gordijn SJ, Abdel-Aleem H, Bergsjo P, Betran A, Duke CW, et al. Making stillbirths count, making numbers talk - issues in data collection for stillbirths. BMC Pregnancy Childbirth. 2009;9:58. doi:10.1186/1471-2393-9-58.

18. Gordijn SJ, Korteweg FJ, Erwich JJHM, Holm JP, van Diem MT, Bergman KA, et al. A multilayered approach for the analysis of perinatal mortality using different classification systems. Eur J Obstet Gynecol Reprod Biol. 2009;144(2):99-104.

19. Hovatta O, Lipasti A, Rapola J, Karjalainen O. Causes of stillbirth: a clinicopathological study of 243 patients. Br J Obstet Gynaecol. 1983;90(8):691-6.

20. Manktelow BM, Smith LK, Evans TA, Hyman-Taylor P, Kurinczuk JJ, Field DJ, et al. UK Perinatal Mortality Surveillance Report UK Perinatal Deaths for births from January to December 2013. Leicester: The Infant Mortality and Morbidity Group, Department of Health Sciences, University of Leicester; 2015.

21. Manktelow BM, Smith LK, Seaton SE, Hyman-Taylor P, Kurinczuk JJ, Field DJ, et al. UK Perinatal Mortality Surveillance Report UK Perinatal Deaths for Births from January to December 2014. Leicester: The Infant Mortality and Morbidity Group, Department of Health Sciences, University of Leicester; 2016.

22. World Health Organization. International statistical classification of diseases and related health problems. 10th ed. Geneva: World Health Organization; 2004.

23. Chan A, King JF, Flenady V, Haslam RH, Tudehope DI. Classification of perinatal deaths: development of the Australian and New Zealand classifications. J Paediatr Child Health. 2004;40(7):340-7.

24. Kidanto HL, Mogren I, van Roosmalen J, Thomas AN, Massawe SN, Nystrom L, Lindmark G. Introduction of a qualitative perinatal audit at Muhimbili National Hospital, Dar es Salaam, Tanzania. BMC Pregnancy Childbirth. 2009;9:45.

25. Lawn JE. Estimating the causes of 4 million neonatal deaths in the year 2000. Int J Epidemiol. 2006;35(3):706-18.

26. Manning E, Corcoran P, Meaney S, Greene RA, on behalf of the Perinatal Mortality Group. Perinatal Mortality in Ireland Annual Report 2011. Cork: National Perinatal Epidemiology Centre; 2013.

27. Pattinson RC, De Jong G, Theron GB. Primary causes of total perinatally related wastage at Tygerberg Hospital. S Afr Med J. 1989;75(2):50-3.

28. Schmiegelow C, Minja D, Oesterholt M, Pehrson C, Suhrs HE, Boström S, Lemnge M, Magistrado P, Rasch V, Lusingu J, Theander TG, Nielsen BB. Factors associated with and causes of perinatal mortality in northeastern Tanzania. Acta Obstet Gynecol Scand. 2012;91(9):1061-8.

29. Varli IH, Petersson K, Bottinga R, Bremme K, Hofsjö A, Holm M, Holste C, Kublickas M, Norman M, Pilo C, Roos N, Sundberg A, Wolff K, Papadogiannakis N. The Stockholm classification of stillbirth. Acta Obstet Gynecol Scand. 2008;87(11):1202-12.

30. Wigglesworth JS. Monitoring perinatal mortality. A pathophysiological approach. Lancet. 1980;2(8196):684-6.

31. Abdellatif M, Battashi AA, Ahmed M, Bataclan MF, Khan AA, Maniri AA. The patterns and causes of neonatal mortality at a tertiary Hospital in Oman. Oman Med J. 2013;28(6):422-6.

32. Centre for Maternal and Child Enquiries (CMACE). Perinatal mortality 2008: United Kingdom. London: CMACE; 2010.

33. Engmann C, Garces A, Jehan I, Ditekemena J, Phiri M, Mazariegos M, Chomba E, Pasha O, Tshefu A, McClure EM, Thorsten V, Chakraborty H, Goldenberg RL, Bose C, Carlo WA, Wright LL. Causes of community stillbirths and early neonatal deaths in low-income countries using verbal autopsy: an International, Multicenter Study. J Perinatol. 2011;32(8):585-92.
34. Khanum F. Perinatal mortality-one year analysis at tertiary care hospital of Peshawar. J Postgrad Med Inst. 2009;23(3):267-71.

35. Kidron D, Bernheim J, Aviram R. Placental findings contributing to fetal death, a study of 120 stillbirths between 23 and 40 weeks gestation. Placenta. 2009;30(8):700-4.

36. Mo-suwan L, Isaranurug S, Chanvitan P, Techasena W, Sutra S, Supakunpinyo C, et al. Perinatal death pattern in the four districts of Thailand: findings from the Prospective Cohort Study of Thai Children (PCTC). J Med Assoc Thai. 2009;92(5):660-6.

37. The MRC Unit for Maternal and Infant Health Care Strategies, PPIP Users, National Department of Health. Saving Babies 2002: Third Perinatal Care Survey of South Africa. 2002.

38. National Services Scotland. Scottish perinatal and infant mortality and morbidity report 2011. Edinburgh: National Services Scotland; 2013.

39. National Institute of Population Research and Training (NIPORT), Mitra and Associates, ORC Macro. Bangladesh Demographic and Health Survey 2004. Dhaka: National Institute of Population Research and Training, Mitra and Associates, and ORC Macro; 2005.

40. Shah BD, Dwivedi LK. Causes of Neonatal Deaths among Tribal Women in Gujarat, India. Popul Res Policy Rev. 2011;30(4):517-36.

41. van Diem M, De Reu P, Eskes M, Brouwers H, Holleboom C, Slagter-Roukema T, Merkus H. National perinatal audit, a feasible initiative for the Netherlands!? A validation study. Acta Obstet Gynecol Scand. 2010;89(9):1168-73.

42. VanderWielen B, Zaleski C, Cold C, McPherson E. Wisconsin stillbirth services program: a multifocal approach to stillbirth analysis. Am J Med Genet A. 2011;155(5):1073-80.

43. Wood AM, Pasupathy D, Pell JP, Fleming M, Smith GCS. Trends in socioeconomic inequalities in risk of sudden infant death syndrome, other causes of infant mortality, and stillbirth in Scotland: population based study. BMJ. 2012;344:e1552.

44. Basys V, Drazdienë N, Vezbergienë N, Isakova J. Gimimø medicininiai duomenys [Medical data of Births 2013]. Vilnius: Institute of Hygiene Health Information Centre, Vilnius University Medical Faculty, Vilnius University, Centre of Neonatology; 2014

45. Centre for Maternal and Child Enquiries (CMACE). Perinatal Mortality 2009: United Kingdom. London: CMACE; 2011.

46. Cole S, Hartford RB, Bergsjø P, McCarthy B. International Collaborative Effort (ICE) on Birth Weight, Plurality, Perinatal, and Infant Mortality: III: a method of grouping underlying causes of infant death to aid international comparisons. Acta Obstet Gynecol Scand. 1989;68(2):113-7.

47. De Reu P, Van Diem M, Eskes M, Oosterbaan H, Smits L, Merkus H, Nijhuis J. The Dutch Perinatal Audit Project: a feasibility study for nationwide perinatal audit in the Netherlands. Acta Obstet Gynecol Scand. 2009;88(11):1201-8.

48. Gardosi J. Classification of stillbirth by relevant condition at death (ReCoDe): population based cohort study. BMJ. 2005;331(7525):1113-7.

49. Glinianaia SV, Rankin J, Pearce MS, Parker L, Pless-Mulloli T. Stillbirth and infant mortality in singletons by cause of death, birthweight, gestational age and birthweight-for-gestation, Newcastle upon Tyne 1961-2000. Paediatr Perinat Epidemiol. 2010;24(4):331-42.

50. Hey EN, Lloyd DJ, Wigglesworth JS. Classifying perinatal death: fetal and neonatal factors. BJOG. 1986;93(12):1213-23.

51. Hinderaker SG, Olsen BE, Bergsjo PB, Gasheka P, Lie RT, Havnen J, Kvale G. Avoidable stillbirths and neonatal deaths in rural Tanzania. BJOG. 2003;110(6):616-23.

52. Manandhar SR, Ojha A, Manandhar DS, Shrestha B, Shrestha D, Saville N, Costello AM, Osrin D. Causes of stillbirths and neonatal deaths in Dhanusha district, Nepal: a verbal autopsy study. Kathmandu Univ Med J. 2010;8(29):62-72.

53. Nausheen S, Soofi SB, Sadiq K, Habib A, Turab A, Zahid M, Imran Khan M, Suhag Z, Bhatti Z, Ahmed I, Bahl R, Bhutta S, Bhutta ZA, Carlo WÂA. Validation of verbal autopsy tool for ascertaining the causes of stillbirth. PLOS ONE. 2013;8(10):e76933.

54. Nga NT, Hoa DTP, Målqvist M, Persson L- $\AA$, Ewald U. Causes of neonatal death: results from NeoKIP community-based trial in Quang Ninh province, Vietnam. Acta Paediatr. 2012;101(4):368-73.

55. The Stillbirth Collaborative Research Network Writing Group. Causes of death among stillbirths. J Am Med Assoc. 2011;306(22):2459-68.

56. Simpson CDA, Ye XY, Hellmann J, Tomlinson C. Trends in cause-specific mortality at a Canadian outborn NICU. Pediatrics. 2010;126(6):e1538-44.

57. Singh A, Toppo A. Re. Co. De.: a better classification for determination of still births. J Obstet Gynaecol India. 2011;61(6):656-8. 
58. Aggarwal AK, Jain V, Kumar R. Validity of verbal autopsy for ascertaining the causes of stillbirth. Bull World Health Organ. 2011;89(1):31-40.

59. Aggarwal AK, Kumar P, Pandit S, Kumar R, Eisele T. Accuracy of WHO verbal autopsy tool in determining major causes of neonatal deaths in India. PLOS ONE. 2013;8(1):e54865.

60. Dias e Silva CMC, Gomes KRO, Rocha OAMS, de Almeida IMLM, Neto JMM. Validity and reliability of data and avoidability of the underlying cause of neonatal deaths in the intensive care unit of the North-Northeast Perinatal Care Network [Portuguese]. Cad Saude Publica. 2013;29(3):547-56.

61. Dudley DJ, Goldenberg R, Conway D, Silver RM, Saade GR, Varner MW, Pinar H, Coustan D, Bukowski R, Stoll B, Koch MA, Parker CB, Reddy UM. A new system for determining the causes of stillbirth. Obstet Gynecol. 2010;116(2, Part 1):254-60.

62. Khanal S, GC VS, Dawson P, Houston R. Verbal autopsy to ascertain causes of neonatal deaths in a community setting: a study from Morang, Nepal. JNMA J Nepal Med Assoc. 2011:51(181):21-7.

63. Lawn JE, Mohammad Y, Haws RA, Tanya S, Darmstadt GL, Bhutta ZA. 3.2 million stillbirths: epidemiology and overview of the evidence review. BMC Pregnancy Childbirth. 2009;9 Suppl 1:S2.

64. Lawn JE, Kinney MV, Black RE, Pitt C, Cousens S, Kerber K, Corbett E, Moran AC, Morrissey CS, Oestergaard MZ. Newborn survival: a multi-country analysis of a decade of change. Health Policy Plan. 2012;27 suppl 3:iii6-iii28.

65. Olamijulo JA, Olaleye O. Perinatal mortality in Lagos University Teaching Hospital: a five year review. Nig Q J Hosp Med. 2011;21(4):255-61.

66. Seaton SE, Field DJ, Draper ES, Manktelow BN, Smith GCS, Springett A, Smith LK. Socioeconomic inequalities in the rate of stillbirths by cause: a population-based study. BMJ Open. 2012;2(3):e001100.

67. Serena C, Marchetti G, Rambaldi MP, Ottanelli S, Di Tommaso M, Avagliano L, Pieralli A, Mello G, Mecacci F. Stillbirth and fetal growth restriction. J Matern Fetal Neonatal Med. 2012;26(1):16-20.

68. Winbo I. NICE, a new cause of death classification for stillbirths and neonatal deaths. Neonatal and Intrauterine Death Classification according to Etiology. Int J Epidemiol. 1998;27(3):499-504.

69. Winter R, Pullum T, Langston A, Mivumbi NV, Rutayisire PC, Muhoza DN, et al. Trends in Neonatal Mortality in Rwanda, 2000-2010. Calverton: ICF International; 2013

70. Cunningham F, Leveno K, Bloom SL, Hauth JC, Rouse DJ, Spong CY, editors. Williams obstetrics. 23rd ed. New York: McGraw-Hill; 2010.

71. Freitas BAC, Goncalves MR, Ribeiro RCL. Infant mortality according to preventable causes and components - Vicosa-MG, 1998-2010. [Portuguese]. Pediatria Moderna. 2012;48(6):237-45.

72. Gupta SS. Identification of causes of under-five deaths in health facilities in Bhutan Ministry of Health of the Royal Government of Bhutan. 2012.

73. Hama Diallo A, Meda N, Sommerfelt H, Traore GS, Cousens S, Tylleskar T. The high burden of infant deaths in rural Burkina Faso: a prospective community-based cohort study. BMC Public Health. 2012;12(1):739.

74. Jehan I. Neonatal mortality, risk factors and causes: a prospective population-based cohort study in urban Pakistan. Bull World Health Organ. 2009;87(2):130-8.

75. Kruse AY, Phuong CN, Ho BTT, Stensballe LG, Pedersen FK, Greisen G. Identification of important and potentially avoidable risk factors in a prospective audit study of neonatal deaths in a paediatric hospital in Vietnam. Acta Paediatr. 2014;103(2):139-44.

76. Nabeel M, Bushra M, Anum Y, Muneer A, Jai K. The study of etiological and demographic characteristics of neonatal mortality and morbidity - a consecutive case series study from Pakistan. BMC Pediatr. 2012;12:131.

77. Public Health Agency of Canada. Canadian Perinatal Health Report. 2008th ed. Ottawa: Public Health Agency of Canada; 2008

78. Rocha R, Oliveira C, Karina Ferreira D, Bonfim C. Neonatal mortality and avoidability: an epidemiological profile analysis [Portuguese]. Rev Enferm UERJ. 2011;19(1):114-20.

79. Smith LK, Manktelow BN, Draper ES, Springett A, Field DJ. Nature of socioeconomic inequalities in neonatal mortality: population based study. BMJ. 2010;341:c6654

80. Wou K, Ouellet M-P, Chen M-F, Brown RN. Comparison of the aetiology of stillbirth over five decades in a single centre: a retrospective study. BMJ Open. 2014;4(6):e004635.

81. Cunningham FG, Hollier LM. Fetal death. In: Williams obstetrics. 20th ed (Suppl 4) ed. Norwalk: Appleton \& Lange; 1997.

82. Flenady V, Froen JF, Pinar H, Torabi R, Saastad E, Guyon G et al. An evaluation of classification systems for stillbirth. BMC Pregnancy Childbirth. 2009;9:24.

\section{Submit your next manuscript to BioMed Central and we will help you at every step:}

- We accept pre-submission inquiries

- Our selector tool helps you to find the most relevant journal

- We provide round the clock customer support

- Convenient online submission

- Thorough peer review

- Inclusion in PubMed and all major indexing services

- Maximum visibility for your research

Submit your manuscript at www.biomedcentral.com/submit
Biomed Central 